\title{
Modelling Price Transmission within the Supply Chain under a European Protected Designation of Origin Framework: The Case of Parmigiano Reggiano in Italy
}

\author{
Hugo Ferrer-Pérez ${ }^{1}\left(\mathbb{D}\right.$, Filippo Arfini $^{2}\left(\mathbb{D}\right.$ and José M. Gil ${ }^{3, *(1)}$ \\ 1 Applied Mathematics and Statistics, University CEU San Pablo, 28003 Madrid, Spain; \\ hugo.ferrerperez@ceu.es \\ 2 Department of Economics and Management, University of Parma, 43125 Parma, Italy; filippo.arfini@unipr.it \\ 3 CREDA-UPC-IRTA, 08860 Castelldefels, Spain \\ * Correspondence: chema.gil@upc.edu; Tel.: +34-935521210
}

Received: 27 January 2019; Accepted: 4 March 2019; Published: 8 March 2019

\begin{abstract}
Lately, we have witnessed how European Institutions have directed many efforts at improving the effectiveness of food quality schemes (FQS) to address the increasing complexity that has affected all elements of the operating structure of agrifood supply chains worldwide, especially prices. In this paper, we conduct a comparative analysis of the price transmission process in the dairy sector between farm and retail markets within the protected designation of origin (PDO) framework and its non-protected counterpart in Italy. This paper considers a unique dataset for the PDO Parmigiano Reggiano cheese and for a non-protected counterpart in Italy covering a recent period after the price crises that took place nearly a decade ago. A multivariate error correction type approach was estimated together with the corresponding impulse response functions to provide useful insights for understanding the differences in the performance of the price transmission process between protected and non-protected food products. Contrary to most of the previous literature, our results support the hypothesis of symmetric price dynamics along the PDO cheese supply chain. The fewer number of farmers reduces the market power at the retail level generating more efficient price transmission dynamics. Short-run dynamics suggest that in the PDO cheese market farmers and retailers react quicker and with a similar magnitude to market changes, while in the conventional cheese market, retailers benefit in the short run from quicker and of higher magnitude responses to unanticipated market shocks.
\end{abstract}

Keywords: price transmission; protected designation of origin; supply chain; applied econometrics; error correction type model; differentiation; market power

\section{Introduction}

Three decades ago, some European Union Member States started to encourage and protect some specific food products according to their principles that in some case, some of them were quite disparate. Against this background, the European Union was forced to find a convincing solution (inspired by existing national systems) with the sole objective of establishing uniform and fair conditions of competition to protect food products. In the earlies 1990s, the European Union set this quality system with a twofold objective: On the one hand, to ensure any consumer of any EU State Member that the production or processing of agri-food products is strictly controlled with the highest standards or connected with a particular territory and, on the other hand, to protect regional producers 
and provide them with a powerful tool to benefit the commercialization of those quality products with a significant comparative advantage (European Commission (2006) and Dimara et al. (2004)).

In this regulatory framework, European food policies have met consumers' preferences, which are more and more focused on products whose characteristics may be differentiated from the rest of products, due to a greater certified quality. In this sense, the European program of label/certification schemes for quality production is designed to ensure the future of agriculture and assist rural development, as well as providing consumers with better information for purchasing decisions (European Commission (2006)). Moreover, the constant search of a more environmentally-friendly from both producers and consumers in the European Union (EU) along with the economic, environmental and social issues of conventional procedures has led into a greater boost of the quality products especially, those organic or under an official quality specification at the expense of conventional products.

The result is a new quality certified marketing chain whose structural characteristics deserve to be analyzed, in particular, the dynamics of prices in both the long-run and short-run so as to assess the performance of such schemes in reducing the price volatility, as well as satisfying the needs of a growing number of interested agents (producers, consumers, institutions). Food quality policy has attracted the growing interest of agricultural economists from different perspectives, especially from consumers' (inter alia, Bonnet and Simioni (2001); McCluskey and Loureiro (2003); Angulo and Gil (2007); Vecchio and Annunziata (2011); Verbeke et al. (2012); Rousseau and Vranken (2013) and Sckokai et al. (2013)) or or food industry (see McCorriston et al. (2001); Bouamra-Mechemache and Chaaban (2010); Carbone et al. (2014) for instance), but it seems that the analysis of the price transmission mechanism within the supply chain has been rarely conducted for FQS products, which, in our view, should be needed to have a complete knowledge of the effects of such food policy along the whole marketing chain, especially, after the oil price increases of 2007 and 2008.

As opposed to conventional food sectors, for which the literature offers a large body of empirical studies in price transmission and market integration (recent surveys of Meyer and Von Cramon-Taubadel (2004); Listorti and Esposti (2012) and Esposti and Listorti (2013) to name a few of the most recent, Goodwin and Harper (2000) for pork; Ben Kaabia et al. (2005) for poultry; Lloyd et al. (2006) for beef; Ben Kaabia and Gil (2007) for lamb; Ahn and Lee (2015) for fresh fruits), the gap for quality food products linked to terroir has not been fulfilled yet as no published works have addressed this approach to date, though the recent study of Antonioli et al. (2018) for organic milk is a close attempt for quality-differentiated products. On this point, we should point out the difficulty of accessing data prices of these kinds of protected quality products because the information available from the statistical services of government agencies and respective regulatory councils is normally limited and when it exists normally is incomplete. This fact may be one reason behind the lack of empirical studies.

Despite the vast literature on price transmission analysis along food supply chains and in the recent context of the increasing complexity of food supply chains, no comparisons between quality and non-quality designated food products can be made so far. So, our paper is hence the first attempt to fill this gap in the literature. In particular, we explore the price transmission process along the supply chain (from farm to retail levels) for a protected designation of origin (PDO) dairy product in Italy. Especially, we focus on the PDO Parmigiano Reggiano cheese and the generic Caciotta cheese.

As the number of farmers producing the PDO product is significantly lower than in the case of the conventional counterpart and retailers are not able to buy these products in geographically separated markets, this is expected to result in a reduction in the market power at the retail level. As a consequence, we hypothesize that price fluctuations in the PDO cheese, due to unexpected supply and demand changing conditions, will be of the same magnitude both at the farm and retail levels. Moreover, we expect a quicker price transmission mechanism along the food supply chain in relation to the conventional product. To test this hypothesis, we perform a vector error correction model and compute impulse response functions to analyze the long-run and short-run dynamics respectively. 
The obtained results allow us to determine potential explanations for the differences between both markets and to assess whether the price transmission may be benefited from being under such a European quality label. Results from this study can be of interest for policy makers in the sense that if our hypothesis of a reduction of retailers' market power in PDO products holds, this could be a good argument for maintaining the promotion of differentiated Quality Schemes in the EU food sector.

To this end, we organize this paper as follows. In Section 2, we provide a sound description of the PDO Parmigiano Reggiano cheese in Italy. In Section 3, we describe the methodological approach used. In Section 4, we present the data set, report and discuss the results. Section 5 concludes the paper.

\section{Protected Designation of Origin Parmigiano Reggiano in Italy}

In Italy, the milk supply chain is strongly conditioned by the high production of PDO cheeses. In 2016 (last year available) 47\% of the cow milk produced was used to produce PDO cheeses (Assolatte 2017). In particular, two cheeses alone use about $40 \%$ of the available milk (23\% for Grana Padano PDO and 16\% for Parmigiano Reggiano PDO), while the others PDO cheeses from cow milk represent the $0.09 \%$ of the national milk production. Despite Parmigiano Reggiano is the second cheese produced (in volume), it is the most famous Italian cheese in the world. Its reputation is strictly linked to the production system that reflects the social economic structure of the dairies in the Parmigiano-Reggiano area. Nowadays the quality level of the cheese and the agent behavior is strongly oriented by the PDO Inter-branch Organization (Parmigiano Reggiano Consortia) (Giacomini et al. 2012).

As a PDO product, milk and cheese production must coincide in the same territory defined by the code of specification and represented by the provinces of Parma, Reggio Emilia, Modena, part of Bologna (left the province of the Rhine River) and part of the Mantua province (south of the river Po). Moreover, the hay used to feed the cows must be produced mainly in the territory of production, while the seasoning of the cheese (up to 12 months). The supply chain of this famous cheese collects about $15 \%$ of Italian milk production. However, the consumption of Parmigiano Reggiano is not confined within the typical area, indeed, most of the cheese produced is sold in the national and European market. It can be said that the Parmigiano Reggiano system has its roots in the typical area, but has important commercial relationships also with other regions, while the value chain extends widely the boundary outlined by the typical area (Arfini and Mancini 2013).

The structure, organization and its strategies for the production and marketing of Parmigiano Reggiano can be considered the result of a process where different actors with various interests, found a functional balance. In productive and structural terms Parmigiano-Reggiano it is characterized by an overall production of cheese slightly higher than three million forms obtained in 393 dairies, of which 257 managed in cooperative form, which in turn collect the milk of 3000 farms. (Production year of 2017). The value chain is therefore made up of breeders, dairies, traders, and the distribution network. While the farmers and dairies act exclusively within the territory, traders can perform their curing action (12 months of seasoning) even outside the typical area moving into warehouses in other regions.

The production of Reggiano-Parmesan cheese starts from the stables of milk producers, whose production takes place in compliance with the production specification, which obtains a high dairy milk attitude in tune with a handicraft production process. Milk production is then delivered to dairies. Within the supply chain there are three categories of breeders: (i) Farmers who give milk to cooperative dairies and therefore members of the same cooperatives; (ii) dairy farmers who donate milk to non-cooperative dairies classified as artisanal or industrial (based on the volume of processed milk); (iii) dairy farmers self-conferring milk in their own dairy. This feature is very important, because it is the productive decisions of the agricultural companies that influence the trend of the milk supply and, therefore, of cheese. As a consequence, the behavior and strategies of the farms are of fundamental importance, since they influence, in turn, the strategies of the dairies. The production strategies and control of the offer, however, are decided by breeders who, according to EU Regulation 1151/2012, 
own a "cheese quota", which in fact coincides with the milk produced. The exceeding of the quota involves the payment of a fine to the Consortium, which will use it to promote cheese in the markets.

The dairies of the Parmigiano-Reggiano system have the main characteristic of being a single-product company represented by Parmigiano Reggiano cheese and its derivatives (cream, butter, whey, ricotta). Moreover, in this case there are three different types of dairies: (i) Cooperatives; (ii) non-cooperative; (iii) artisanal. The cooperative dairies represent the main productive component of the Parmigiano-Reggiano system. This type of firms represents about $60 \%$ of dairies. Their commercial strategy is to season the cheese for up to 12 months and then sell all the production to seasonal-wholesalers, who in turn, age the cheese until 24 months. Then, the cheese is sold directly to the commercial distribution (Arfini et al. 2006).

In the functioning of the value chain of Parmigiano Reggiano, the role of seasoning by tradres (12, 18 or 24 months of maturing is crucial in defining the price. Their commercial action is placed between dairies and distribution channels. The cheese is purchased in large homogeneous batches from dairies (usually three times of the year) and is sold in smaller volumes (in forms or packaged under vacuum) to the commercial distribution. Wholesalers, on one side set the price of cheese with dairies, but on the other hand, become "price taker" when they sell cheese to retailers.

Overall, the value chain of Parmigiano-Reggiano has some characteristics that influence its operation and efficiency: (i) It is a chain with a high level of information asymmetry. Prices of cheese lots sold by dairies are not known, is known only the "average price" of transactions made by the chambers of commerce after a negotiation between the agents that make up the commission. (ii) the wholesale market is characterized by the presence of oligopolists able to influence the price; (iii) the quality of the cheese does not affect the wholesale price. In this respect, even if it is a famous PDO, the Parmigiano-Reggiano has a similar trend to commodity goods; (iv) the retail strategy is unfair: Under the umbrella brand of the Parmigiano Reggiano there are no strong dairy or industrial brands and retailers often sell the cheese below cost to attract and retain customers. This behavior, even if it debatable, is allowed since there are not internal rules governing the issue of minimum prices or the setting of retail prices; the analysis of market trend at retail level is complex, since prices are collected by retail companies through Iri Infoscan or Nielsen and sell privately to stakeholders interested to know price evolution. All these aspects make the market of Parmigiano Reggiano a "black-box" where is very hard to know the dynamics of the agents and the distribution of value along the chain.

\section{Methodological Approach}

Understanding the price transmission process along the food supply chain maintains the interest among agricultural researchers because of its relevant implications for social and policy levels. Though the usual theoretical model underlying this sort of empirical studies assumes symmetric behavior in the transmission process which may be considered as clear evidence of an efficient market, recent works found the presence of significant asymmetries for which the debate on the underlying causes still continues to linger (see, for instance, Antonioli et al. 2018 for a brief review). What is common in this debate is the presence of a threshold value that becomes a crucial figure in current alternative models used in this sort of empirical studies.

Our approach may be summarized by the following stages: In the first stage, we test the integration order of the price series considered in our models and if the unit root null is non-rejected then we test for cointegration. In the second stage, we test for asymmetries in the price transmission process. In the last stage, we estimate the corresponding model based on the decision made in the second stage to assess how prices are transmitted along chain actors of the food supply chain and explain the differences or similarities that exist between the quality protected and non-quality protected product.

That being so, this study employs some of the most recent contributions to the unit root literature. In particular, we consider some unit root tests (namely, the modified Sargan and Bargava test, hereafter, MSB test) proposed by the influential paper of $\mathrm{Ng}$ and Perron (2001) instead of the standard DF-type 
or PP tests. However, the decision made based on this test is not valid when a structural break exists in the time series because it is well known that their outcome is biased towards the non-rejection of the null. To deal with this problem, we apply the proposal by Carrion-i-Silvestre et al. (2009) to test for the presence of multiple unknown structural breaks in the level, intercept or intercept and slope of the series. Moreover, we test the null of stationarity against the alternative of the existence of a unit root in the series for confirmation purposes by means of the popular stationarity test of Kwiatkowski et al. (1992), hereafter, KPSS test.

As claimed by Myers (1994), normally many commodity prices are characterized as co-integrated which implies that nonstationary price time series share a trend in the long-run, and there are no incentives to deviate from this situation. But, if any unanticipated shock appears, there is a tendency to revert to the equilibrium. In this sense, the literature offers two widely used approaches: On the one hand, the approach developed by Engle and Granger (1987) which relies on a two-step estimator to test the parameters of a bivariate single-equation model; and, on the other hand, the Johansen (1988) approach, which consists of a maximum likelihood ratio test to test multiple co-integrating vectors. In this study, we follow the latter and apply the Bartlett corrected trace test to ensure reduced size distortions in the trace tests, due to the short-run effects of the VAR model (Johansen 2002).

Once the presence of a long-term equilibrium relationship between the two-price series in each market, we test whether nonlinearities exist in the adjustment process. To do so, we follow Lo and Zivot (2001) the null of linearity against multivariate threshold vector error correction model (TVECM) by means of LR tests. Thus, in the first place we test for the null of a linear VECM against a two-regime TVECM considering the cointegration relationship as the threshold variable, and then we test for the null of a linear VECM against a three-regime TVECM, again considering the cointegration relationship as the threshold variable. If the null can be rejected, the threshold model is more appropriate to characterize the nonlinear dynamic adjustments of prices in the market. Otherwise, the linear model may be the best fit.

After the estimation of the dynamic price relationships in the long-term, we will explore the dynamics in the short-run by computing orthogonalized impulse response functions, henceforth IRFs, to measure how the deviations from the equilibrium adjust. This is of great interest to deepen the understanding of the dynamic relationships between prices along chain actors as they provide useful information about the size and persistence of the response of a specific variable to an unanticipated change in the other variable over time.

\section{Empirical Results and Discussion}

In this section, we present the results of the empirical analysis. Our dataset ${ }^{1}$ contains the usual farm-retail pairwise prices, measured in $€ / \mathrm{kg}$, for the PDO Parmigiano Reggiano cheese and the generic Caciotta cheese covering the period from 2011 to 2015, and observed with weekly frequency, as shown in Figure 1. In total, 260 observations per series. Looking at this figure, one may observe each pair of prices sharing a relationship in the long-term, being retail prices much more volatile than farm prices with limited responses of the latter. Also, all the prices exhibit visible fluctuations along with a decreasing trend for the quality cheese and a positive trend for the non-quality cheese.

1 Data were extracted from Istituto di Servizi per il Mercato Agricolo Alimentare (ISMEA) database and contains farm prices, which are prices paid to dairy firms (cheese producers) by wholesalers (who normally continue to ripening) or by distributors (because the producer side is highly fragmented, and only the biggest Parmigiano producers may sell it directly to distributors), and retail or consumer prices which are prices paid by consumers on the final market. 


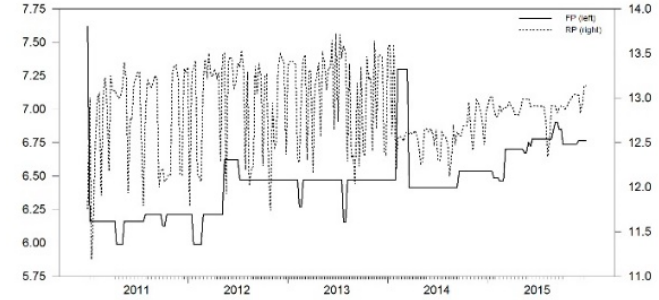

(a)

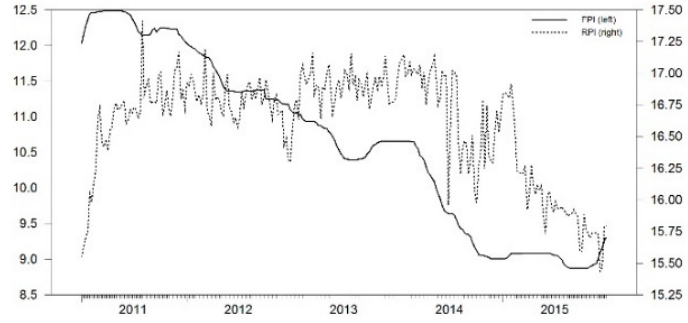

(b)

Figure 1. Evolution of Farm-Retail price series. (a) Farm-Retail prices for Generic Caciotta cheese; (b) Farm-Retail prices for protected designation of (PDO) Parmigiano Reggiano cheese.

Now, we report Table 1, which contains a summary of some basic descriptive statistics along with some preliminary tests. All price series were transformed into logs to reduce the potential fluctuations according, for instance, to Hamilton (1994). According to the results obtained, we can exclude for three out of four series the presence of a linear trend. Unit root and stationary tests were applied to the series accordingly (Table 2). Also, we tested for the presence of multiple structural changes under the null and the alternative hypotheses as in Carrion-i-Silvestre et al. (2009) to avoid the bias of standard unit root tests towards non-rejection of the unit root null when a change is present (Table 3). Results confirm that all the series considered are integrated of order 1.

Table 1. Summary of descriptive statistics.

\begin{tabular}{ccccc}
\hline & FP & RP & FPI & RPI \\
\hline Mean & 6.45 & 12.860 & 10.654 & 16.605 \\
Min. & 6.473 & 12.910 & 10.655 & 16.752 \\
Max. & 5.988 & 11.192 & 8.875 & 15.435 \\
Std. deviation & 7.620 & 13.824 & 12.485 & 17.412 \\
Skewness & 0.253 & 0.473 & 1.222 & 0.419 \\
Kurtosis & $0.988^{* * *}$ & $-0.503^{* * *}$ & -0.068 & $-0.948^{* * *}$ \\
JB test & $2.733^{* * *}$ & -0.298 & $-1.328^{* * *}$ & $-0.138^{* * *}$ \\
Engle (1982) & $123.240^{* * *}$ & $11.945^{* * *}$ & $19.300^{* * *}$ & $39.139^{* * *}$ \\
Trend test & $220.225^{* *}$ & $20.924^{* * *}$ & $257.906^{* * *}$ & $208.045^{* * *}$ \\
\hline
\end{tabular}

FP, farm prices for Caciotta cheese; RP, retail prices for Caciotta cheese; FPI, farm prices for PDO cheese; RPI, retail prices for PDO cheese. Engle (1982) tests whether there are autoregressive conditional heteroscedastic (ARCH) effects with 2 lags. ${ }^{* * *}$ denotes statistically significance at $1 \%$ level.

Table 2. Unit root and stationary tests.

\begin{tabular}{ccccc}
\hline & FP & RP & FPI & RPI \\
\hline MSB test & $0.248(1)$ & $0.353(10)$ & $0.247(1)$ & $0.253(3)$ \\
KPSS test & $0.404(0)^{* *}$ & $0.759(0)^{* *}$ & $2.656(0)^{* *}$ & $2.820(0)^{* *}$ \\
\hline
\end{tabular}

FP, farm prices for Caciotta cheese; RP, retail prices for Caciotta cheese; FPI, farm prices for PDO cheese; RPI, retail prices for PDO cheese. MSB test is applied as in Ng and Perron (2001) using the MAIC to select the optimal lag, represented in parentheses. KPSS test is applied as in Kwiatkowski et al. (1992), where the bandwidth parameter is selected following the automatic bandwidth procedure of Andrews (1991) and represented in parentheses. ${ }^{* *}$ denotes statistically significant at $5 \%$ level of significance, since the asymptotic critical values at $5 \%$ level for the constant (trend) case are respectively 0.233 (0.168) for the MSB, and 0.463 (0.146) for the KPSS. 
Table 3. Unit root and stationary tests with structural breaks (Carrion-i-Silvestre et al. 2009).

\begin{tabular}{ccccc}
\hline & FP & RP & FPI & RPI \\
\hline ADF & -2.775 & $-2.041(-3.289)$ & $-2.342(-3.835)$ & $-2.216(-3.443)$ \\
MSB & $(-3.312)$ & $0.201(0.160)$ & $0.224(0.129)$ & $0.229(0.143)$ \\
Time-break & $0.300(0.161)$ & $2011: 27(27)$ & $2013: 5(107) ;$ & $2013: 4(106)$ \\
\hline
\end{tabular}

FP, farm prices for Caciotta cheese; RP, retail prices for Caciotta cheese; FPI, farm prices for PDO cheese; RPI, retail prices for PDO cheese. The critical value at the 5\% significance level of each test is shown in parentheses. Time-break reflects the date when a structural break was endogenously detected with the corresponding observation in parentheses.

Cointegration may exist when nonstationary variables, in our case, prices, shows a tendency to move together in the long-run and deviations from this equilibrium, due to unexpected shocks tend to revert eventually. In this case, we apply the maximum likelihood ratio test of Johansen (1988) to test multiple cointegrating vectors, which is based on the correct specification of a vector autoregressive model VAR(k) being k the optimal lag length (e.g., Juselius 2006; Enders 2010).

Then, prior to testing for cointegration we select the number of lags of the unrestricted VAR model. Thus, the implementation of usual information criteria reports 2 lags and 3 lags for the quality and non-quality markets, respectively.

Once the lag order has been determined for each system, we test for cointegration and select the cointegration rank using the Bartlett corrected trace test $\lambda_{\text {trace }}^{*}$ as in Johansen (2002). Results are presented in Tables 4 and 5. As prices were considered in logs, we can interpret the cointegration parameters as price elasticities. In fact, the error correction term captures deviations from the long-run relations among prices considered. Thus, for the protected system, we found that farm prices exert higher influence on retail prices with a price elasticity of $11 \%$ whereas for the conventional system, that influence is not significant.

Table 4. Cointegration analysis for PDO cheese.

\begin{tabular}{cccc}
\hline Rank & Eigenvalue & $\lambda_{\text {trace }}^{*}$ & $p$-Value \\
\hline 0 & 0.082 & 28.699 & 0.002 \\
1 & 0.029 & 7.207 & 0.119 \\
\hline
\end{tabular}

Cointegration relationship: ECTI $=R P I_{t}-2.554^{* * *}-0.108^{* * *} F P I_{t}$

*** denotes statistically significant at $1 \%$ level of significance. Results are obtained with the cointegration analysis of time series procedure (CATS) written by (Dennis et al. 2006) in the software regression analysis of time series (RATS) version 9.0.

Table 5. Cointegration analysis for generic Caciotta cheese.

\begin{tabular}{cccc}
\hline Rank & Eigenvalue & $\lambda_{\text {trace }}^{*}$ & $p$-Value \\
\hline 0 & 0.208 & 68.082 & 0.000 \\
1 & 0.035 & 8.995 & 0.053 \\
\hline
\end{tabular}

Cointegration relationship: $\mathrm{ECT}=R P_{t}-2.586^{* * *}+0.018 F P_{t}$

*** denotes statistically significant at $1 \%$ level of significance. Results are obtained with CATS (Dennis et al. 2006) in RATS 9.0.

After having identified the presence of a stationary relationship in the long-run, now we explore whether the adjustment mechanism exhibit nonlinearities following Lo and Zivot (2001). Table 6 reports the obtained results for both markets, the quality and non-quality. In particular, the LR tests indicate for the two markets that the null of the TVECM ${ }_{2}$ against a $\mathrm{TVECM}_{3}$ is rejected at the $1 \%$ level $\left(\mathrm{LR}_{2,3}\right)$, and that null of linearity cannot be rejected at the $5 \%$ significance level in favor of the linear VECM model against the TVECM $3\left(\mathrm{LR}_{1,3}\right)$. Hence, the results confirm the absence of nonlinearities in 
the model specification for the two markets $^{2}$. Consequently, we estimated a VECM for the non-quality and quality markets, respectively. Tables 7 and 8 reports these results, which also ensure the absence of remaining residual autocorrelation.

Table 6. Tests for non-linear adjustments.

\begin{tabular}{ccc}
\hline & PDO Parmigiano Reggiano & Generic Caciotta \\
\hline $\mathrm{LR}_{2,3}$ & $20.66(0.00)$ & $16.20(0.00)$ \\
$\mathrm{LR}_{1,3}$ & $39.58(0.12)$ & $47.45(0.17)$ \\
\hline
\end{tabular}

$L R_{13}$ tests the null hypothesis of linearity against the alternative hypothesis of TVECM model (Lo and Zivot 2001). $L R_{23}$ tests the null hypothesis of TVECM ${ }_{2}$ model against the alternative hypothesis of TVECM 3 (Lo and Zivot 2001). Critical values at the $5 \%$ significance level were presented in parentheses and obtained with the FR bootstrapping technique (Hansen and Seo 2002).

Table 7. Short-run estimates for PDO cheese.

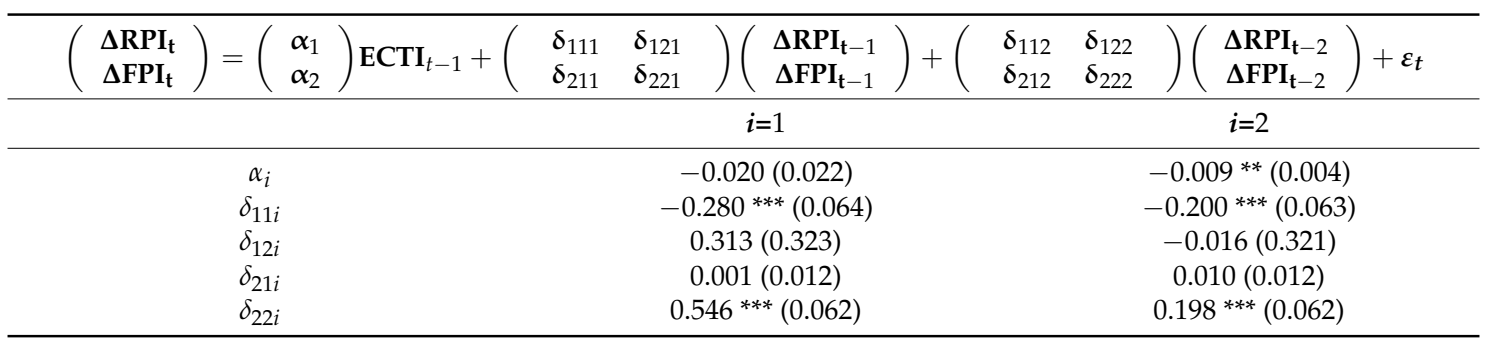

***,** and * denote statistical significance at the 1\%,5\% and 10\% levels, respectively. Standard errors in parenthesis. The residuals pass the multivariate test of Hosking (1981): 37.31 ( $p$-value: 0.87 ) and hence indicates that there all autocorrrelations and lagged cross correlations are zero. Results were obtained with CATS (Dennis et al. 2006) in RATS 9.0 and omitted for ease exposition.

Table 8. Short-run estimates for generic Caciotta cheese.

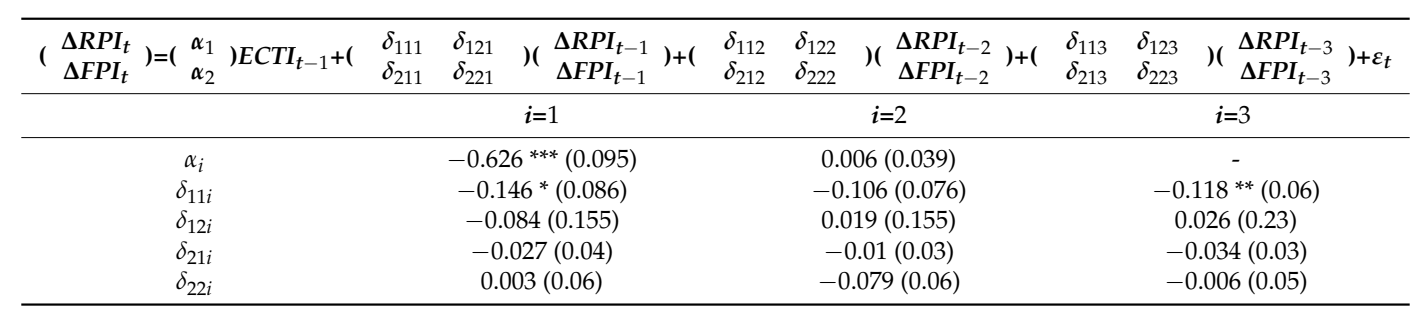

***** and ${ }^{*}$ denote statistical significance at the $1 \%, 5 \%$ and $10 \%$ levels, respectively. Standard errors in parenthesis. The residuals pass the multivariate test of Hosking (1981): 37.31 ( $p$-value: 0.87 ) and hence indicates that there all autocorrrelations and lagged cross correlations are zero. Results were obtained with CATS (Dennis et al. 2006) in RATS 9.0 and omitted for ease exposition.

Thus, we analyze the estimated coefficients, as they are relevant to describe which prices adjust to equilibrium and which do not. The results derived from the two markets indicate that only RP and FP responds in the non-quality and quality markets respectively, while that is true that the response in the quality market is low $(0.09 \%)$.

Now, to better understand the interpretation of the estimated VECMs we compute the impulse response functions (IRFs) because they give information about the characterization of the estimated dynamics of the VECMs by means of measuring the effects of price shocks evolving over time. So, the short-run dynamics are examined by computing the orthogonalized impulse response functions. In this case, Figures 2 and 3 plot the IRFs for the quality and the non-quality product, respectively. Here, we only show the cross responses to any given shock. Figures follow the same structure: In the left panel

2 We found multiple problems of convergence when facing the estimation strategy of the two systems, and the residual tests could not be achieved, due to matrix singularity. What is more, the tests for selecting the transition variable and function contradict each other, and the linear null cannot be rejected. 
(a), we show the retail price reaction to a shock in the downstream level and, the right panel (b) shows the farm price level response to a shock in the upstream level.

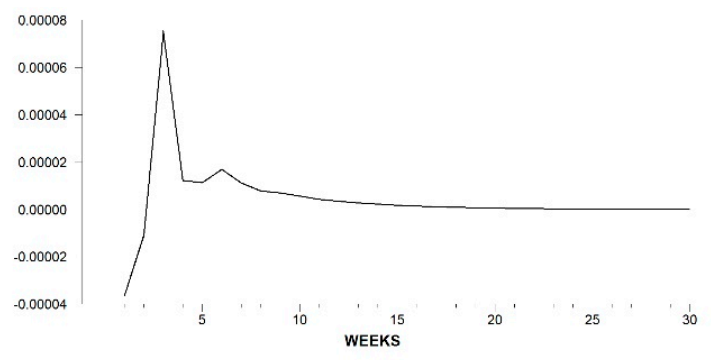

(a)

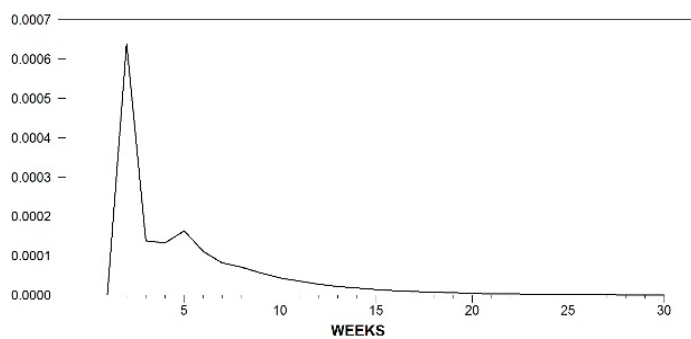

(b)

Figure 2. IRF for PDO Parmigiano Reggiano cheese. (a) Response of retail price to a shock in farm price; (b) Response of farm price to a shock in retail price.

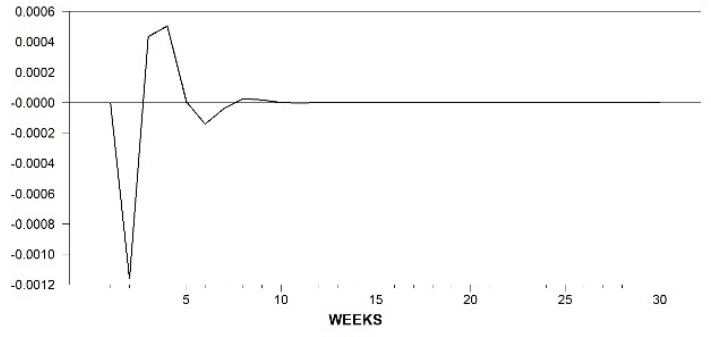

(a)

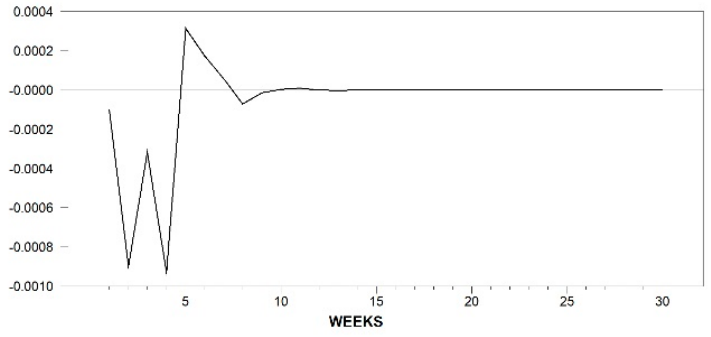

(b)

Figure 3. IRF for the generic Caciotta cheese. (a) Response of retail price to a shock in farm price; (b) Response of farm price to a shock in retail price.

In Figure 2, for the quality cheese, the RPI response is immediate negative and small in magnitude for the first two weeks where it reverts to positive and shows a detrending pattern that collapses to the equilibrium around week 16 . The FPI reaction plotted in (b) is immediate too but slightly higher and positive at each time responsive period, which benefits the farmer for the responsive period by squeezing the margin. The value reaches the equilibrium with some delay, that is, by week 19 .

As we can see in Figure 3, the RP reaction to a shock in FP is not immediate, and for the first three weeks is negative before reverting to positive and briefly fluctuate around the zero-line until the equilibrium is achieved by week 10 . Note that the magnitude in the positive response is less than half of the negative one. Similarly, the response of FP to a shock in RP is immediate and negative until the fifth week where it reverts to positive until the eighth week before reverting again to negative for two more weeks before reaching the equilibrium in week 10. Again, the responsive period as a negative reaction is more significant and longer than being positive, which may imply that when retail prices go up the farmer is quite affected as their prices decrease and hence the margin increases benefiting the retailer.

In this case, data shows that responses in the conventional system indicate that retailers may be benefited when prices increase, and that responses in the quality system suggest that farmers may not be too affected when retail prices go up as they react positively for a long significant period in which the margin is relatively squeezed.

\section{Discussion}

The aim of this study has been to assess the price transmission process within the supply chain of the PDO Parmigiano Reggiano cheese, one of the most famous Italian quality cheeses worldwide. Moreover, this investigation has also offered a comparison with the results of another Italian cheese, the Generic Caciotta, which is not designated with a European food quality label to study whether the 
two markets behave differently as the two cheeses have different characteristics, as well as differences in the structure of their respective supply chain.

Comparison of empirical findings with earlier empirical studies on the price linkages is generally difficult, due to the different characteristics of the dairy products and the perspectives adopted. In this case, this comparison exercise should be carried out with care. Keeping this in mind, we will try to compare our results with those of some relevant applied works that have dealt with the asymmetric price transmission on the dairy sector.

Thus, the obtained empirical results suggest that the farm-retail prices for the two cheese products (quality and conventional) are cointegrated sharing a tendency to move together in the long-term and hence, unexpected shocks will tend to revert in the end to the equilibrium. Also, the results for the two markets do not support the hypothesis of nonlinearities and hence indicate that prices are not subject to asymmetric price transmission. That is, prices do not tend to adjust more quickly when prices decrease that increase. The evidence of no asymmetries for the two cheeses could be somehow consistent with the idea of market power and symmetric price dynamics from McCorriston et al. (2001). Further, they could be sided with mixed evidence found by Awokuse and Wang (2009) who estimated price transmission for US dairy prices (whole milk and Cheddar cheese) using an error correction type model approach. However, it could be said that these results do not support the asymmetries found in the US dairy sector for example by Kinnucan and Forker (1987) or by Serra and Goodwin (2003) for the Spanish dairy sector.

\section{Conclusions}

Given the increasing complexity in modern agrifood supply chains and the wide diversity of products operating in relevant markets, the study of price transmission process along the supply chain has renewed the interest among agricultural economists. This paper provides new insights on the analysis of price transmission mechanism along the marketing chain of food products protected under a European Food Quality Scheme. The focus on food quality products is as a response of the growing interest of consumers, producers and food policy makers in the potential of these labels to augment competitiveness in domestic and international markets, as well as to maintain territorial and social cohesion.

The vast literature on the analysis of price relationships in the agricultural and food markets has mainly focused on how the pricing information is transmitted between chain actors for non-quality products. Hence, there is a gap in the literature because food quality schemes have not been explored yet. Our study contributes to filling this gap and provides novel results on price transmission analysis within the food supply chain under a quality scheme to provide an improved understanding of the performance of quality markets, as well as to compare the differences in the price transmission process among chain actors of their non-quality counterparts.

Our study examines the PDO Parmigiano Reggiano in Italy and considers the generic Caciotta as its non-quality counterpart. Weekly prices were observed for the two products at two levels of the food supply chain for each system, farm and retail. Datasets comprise a relevant period after the rise in prices by the end of 2007 and the relapse by 2011.

To achieve our main aim, we have used a multivariate vector error correction type approach. Our results reveal a long-run equilibrium relationship between farm and retail prices in the two markets. The relationship in the former is not significant, but that in the latter is quite stronger and statistically significant. Non-quality retail prices are characterized by a faster adjustment compared to farm prices, which were characterized by slow adjustments to deviations from the equilibrium, suggesting some degree of retail market power. Conversely, for the Parmigiano Reggiano cheese, farm prices have been characterized by a low adjustment. In this case, retail prices do not show statistically significant responses. As to the dynamics in the short-run, we computed linear impulse response functions. Asymmetries do not appear in both markets. These IRFs suggest that retailers in the non-quality market may benefit when prices go up and that responses for the quality market indicate that farmers 
may not be too affected when retail prices increase because the positive response is for a quite long significant period in which the margin is reduced.

In conclusion, this paper provides novel empirical results on the analysis of the vertical price transmission mechanism along the food supply chain of products designated under a European quality scheme. This is a relevant topic not only for chain actors, but also for policy makers, because it offers useful comparisons of the derived results from the quality products with those of their conventional counterparts to assess the extent to which the transmission mechanism differs along each chain, that is, to measure the differences of the magnitude of the response of prices at different levels of the marketing chain to a shock originating at one particular level of this chain; the speed, direction and nature of the response.

Finally, results should be interpreted with caution. Further research is needed before generalizing the results across the food product portfolio under a European quality scheme and countries. Efforts made by European agents to increase market transparency along the food supply chain have apparently not included food quality schemes. There has not been any systematic data collection for this kind of products, even when the EU is giving some significant support for promotion. We hope transparency will also arrive at FQS and more studies will be carried out to check if these schemes have been a useful tool to increase farmers' market power and to improve the functioning of markets allowing prices to be quickly and fully transmitted along the food supply chain. In any case, this paper may encourage future researches on the price behavior along the supply chain under food quality schemes, as well as the implementation of further methodological refinements.

Author Contributions: The authors equally contributed to the current paper. H.F.-P., J.M.G. and F.A. conceived and designed the current research paper; H.F.-P., J.M.G. and F.A. contributed data collection. H.F.-P. and J.M.G. analyzed the data; H.F.-P., J.M.G. and F.A. wrote the paper and also the subsequent revisions in response to reviewers' comments.

Funding: This research was funded by the European Union's Horizon 2020 research and innovation programme under grant agreement No 678024 for the Strength to Food Project. However, funders had no role in study design, data collection and analysis, decision to publish, or preparation of the manuscript.

Conflicts of Interest: The authors declare no conflict of interest.

\section{References}

Ahn, Byeong-il, and Hyunok Lee. 2015. Vertical Price Transmission of Perishable Products: The Case of Fresh Fruits in the Western United States. Journal of Agricultural and Resource Economics 40: 405-24.

Andrews, Donald W. K. 1991. Heteroskedasticity and autocorrelation consistent covariance matrix estimation. Econometrica 59: 817-58. [CrossRef]

Angulo, Ana M., and José M. Gil. 2007. Risk perception and consumer willingness to pay for certified beef in Spain. Food Quality and Preference 18: 1106-17. [CrossRef]

Antonioli, Federico, Monia Ben Kaabia, Filippo Arfini, and José M. Gil. 2018. Price transmission dynamics for quality-certified food products: A comparison between conventional and organic fluid milk in Italy. Agribusiness, 1-20. [CrossRef]

Arfini, Filippo, and Maria Cecilia Mancini. 2013. Local institutions and territorial competitiveness in the case of Parmigiano Reggiano localised production system. Paper presented at the 2nd AIEAA Conference, "Between Crisis and Development: Which Role for the Bio-Economy", Parma, Italy, June 6-7; Available online: http:/ / ageconsearch.umn.edu/ (accessed on 4 March 2019).

Arfini, Filippo, Stefano Boccaletti, Corrado Giacomini, Daniele Moro, and Paolo Sckokai. 2006. Case studies 8. Parmigiano Reggiano. European Commission. Directorate-General Jrc. Joint Research Centre. Institute for Prospective Technological Studies (Seville). Sustainability in Agriculture. Food and Health. Available online: http:/ / ec.europa.eu/agriculture/quality / certification/docs/case8_en.pdf (accessed on 4 March 2019).

Assolatte. 2017. Industria Lattiero-Casearia Italiana, Rapporto 2016, Andamento del settore, dati e valutazioni statistiche Assemblea Assolatte Milano, 13 giugno 2017. Available online: http://www.assolatte.it/ zpublish/4/uploads/4/news_down/15003858381286528019_Rapporto\%20Assolatte\%202016.pdf (accessed on 4 March 2019). 
Awokuse, Titus O., and Xiaohong Wang. 2009. Threshold Effects and Asymmetric Price Adjustments in U.S. Dairy Markets. Canadian Journal of Agricultural Economics/Revue canadienne d'agroeconomie 57: 269-86. [CrossRef]

Ben Kaabia, Monia, and José M. Gil. 2007. Asymmetric Price Transmission in the Spanish Lamb Sector. European Review of Agricultural Economics 34: 53-80. [CrossRef]

Ben Kaabia, Monia, José M. Gil, and Mehrez Ameur. 2005. Vertical integration and non-linear price adjustments: The Spanish poultry sector. Agribusiness 221: 253-71. [CrossRef]

Bonnet, Céline, and Michel Simioni. 2001. Assessing consumer response to Protected Designation of Origin labelling: A mixed multinominal logit approach. European Review of Agricultural Economics 28: 433-49. [CrossRef]

Bouamra-Mechemache, Zohra, and Jad Chaaban. 2010. Protected Designation of Origin Revisited. Journal of Agricultural \& Food Industrial Organization 8. [CrossRef]

Carbone, Anna, Julia Caswell, Francesca Galli, and Alessandro Sorrentino. 2014. The Performance of Protected Designations of Origin: An Ex Post Multi-Criteria Assessment of the Italian Cheese and Olive Oil Sectors. Journal of Agricultural \& Food Industrial Organization 12: 121-40.

Carrion-i-Silvestre, José Luis, Dulpa Kim, and Pierre Perron. 2009. GLS-Based Unit Root Tests with Multiple Structural Breaks under Both the Null and the Alternative Hypotheses. Econometric Theory 25: 1754-92. [CrossRef]

Dennis, Jonathan G., Henrik Hansen, Søren Johansen, and Katarina Juselius. 2006. CATS in RATS. In Cointegration Analysis of Time Series, Version 2. Evanston: Estima.

Dimara, Efthalia, Anastasia Petrou, and Dimitris Skuras. 2004. Agricultural policy for quality and producers' evaluations of quality marketing indicators: A Greek case study. Food Policy 29: 485-506. [CrossRef]

Enders, Walter. 2010. Applied Econometric Time Series, 3rd ed. Hoboken: John Wiley \& Sons Inc.

Engle, Robert F. 1982. Autoregressive conditional heteroscedasticity with estimates of the variance of United Kingdom inflation. Econometrica 50: 987-1007. [CrossRef]

Engle, Robert F., and Clive W. J. Granger. 1987. Co-Integration and Error Correction: Representation, Estimation, and Testing. Econometrica 55: 251-76. [CrossRef]

Esposti, Roberto, and Giulia Listorti. 2013. Agricultural price transmission across space and commodities during price bubbles. Agricultural Economics 44: 125-39. [CrossRef]

European Commission. 2006. European Policy for Quality Agricultural Products. Luxembourg: Office for Official Publications of the European Communities.

Giacomini, Corrado, Filippo Arfini, and Kees de Roest. 2012. Interprofession and typical products: The case of Parmigiano Reggiano cheese. Sviluppo Locale 37-38: 125-51.

Goodwin, Barry, and Daniel C. Harper. 2000. Price transmission, threshold behavior, and asymmetric adjustment in the U.S. pork sector. Journal of Agricultural and Applied Economics 32: 543-53. [CrossRef]

Hamilton, James H. 1994. Time Series Analysis. Princeton: Princeton University Press.

Hansen, Bruce E., and Byeongseon Seo. 2002. Testing for two-regime threshold cointegration in vector error correction models. Journal of Econometrics 110: 293-318. [CrossRef]

Hosking, J. R. M. 1981. Equivalent forms of the multivariate Portmanteau Statistic. Journal of the Royal Statistic Society B 43: 261-62, Corrigendum: Journal of the Royal Statistic Society B (1989) 51: 303. [CrossRef]

Johansen, Søren. 1988. Statistical analysis of cointegration vectors. Journal of Economic Dynamics and Control 12: 231-54. [CrossRef]

Johansen, Søren. 2002. A Small Sample Correction for the Test of Cointegrating Rank in the Vector Autoregressive Model. Econometrica 70: 1929-61. [CrossRef]

Juselius, Katarina. 2006. The Cointegrated VAR Model: Methodology and applications. In Advanced Texts in Econometrics. Oxford: Oxford University Press.

Kinnucan, Henry W., and Olan D. Forker. 1987. Asymmetry in Farm-Retail Price Transmission for Major Dairy Products. American Journal of Agricultural Economics 69: 285-92. [CrossRef]

Kwiatkowski, Denis, Peter C. B. Phillips, Peter Schmidt, and Yongcheol Shin. 1992. Testing the null hypothesis of stationarity against the alternative of a unit root: How sure are we that economic time series have a unit root? Journal of Econometrics 54: 159-78. [CrossRef]

Listorti, Giulia, and Roberto Esposti. 2012. Horizontal Price Transmission in Agricultural Markets: Fundamental Concepts and Open Empirical Issues. Bio-Based and Applied Economics 1: 81-108. 
Lo, Ming Chien, and Eric Zivot. 2001. Threshold cointegration and nonlinear adjustment to the law of one price. Macroeconomic Dynamics 5: 533-76.

McCluskey, Jill J., and Maria L. Loureiro. 2003. Consumer Preferences and Willingness to Pay for Food Labeling: A Discussion of Empirical Studies. Journal of Food Distribution Research 34: 95-102.

McCorriston, Steve, Wyn Morgan, and Anthony J. Rayner. 2001. Price transmission, market power, marketing chain, returns to scale, food industry. European Review of Agricultural Economics 28: 143-59. [CrossRef]

Meyer, Jochen, and Stephan Von Cramon-Taubadel. 2004. Asymmetric price transmission: A survey. Journal of Agricultural Economics 55: 581-611. [CrossRef]

Myers, Robert J. 1994. Time series econometrics and commodity price analysis: A review. Review of Marketing and Agricultural Economics 62: 167-81.

$\mathrm{Ng}$, Serena, and Pierre Perron. 2001. Lag length selection and the construction of unit root tests with good size and power. Econometrica 69: 1519-54. [CrossRef]

Rousseau, Sandra, and Liesbet Vranken. 2013. Green Market expansion by reducing information asymmetries: Evidence for labeled organic food products. Food Policy 40: 31-43. [CrossRef]

Sckokai, Paolo, Claudio Soregaroli, and Daniele Moro. 2013. Estimating Market Power by Retailers in a Dynamic Framework: The Italian PDO Cheese Market. Journal of Agricultural Economics 64: 33-53. [CrossRef]

Serra, Teresa, and Barry Goodwin. 2003. Price transmission and asymmetric adjustment in the Spanish dairy sector. Applied Economics 35: 1889-99.

Vecchio, Riccardo, and Azzurra Annunziata. 2011. The role of PDO/PGI labelling in Italian consumers' food choices. Agricultural Economics Review 12: 80-98.

Verbeke, Wim, Zuzanna Pieniak, Luis Guerrero, and Margrethe Hersleth. 2012. Consumers' Awareness and Attitudinal Determinants of European Union Quality Label Use on Traditional Foods. Bio-Based and Applied Economics 1: 213-29.

(C) 2019 by the authors. Licensee MDPI, Basel, Switzerland. This article is an open access article distributed under the terms and conditions of the Creative Commons Attribution (CC BY) license (http:/ / creativecommons.org/licenses/by/4.0/). 